\title{
Depressive symptoms and early retirement intentions among Danish eldercare workers: Cross-sectional and longitudinal analyses
}

\author{
Mette Andersen Nexo ${ }^{1 *}$, Vilhelm Borg ${ }^{1}$, Camilla Sandal Sejbaek ${ }^{2}$, Isabella Gomes Carneiro ${ }^{1,3}$,
}

Pernille U. Hjarsbech ${ }^{4}$ and Reiner Rugulies ${ }^{1,2,5}$

\begin{abstract}
Background: Depression increases the risk of disability pension and represents a health related strain that pushes people out of the labour market. Although early voluntary retirement is an important alternative to disability pension, few studies have examined whether depressive symptoms incur early voluntary retirement. This study examined whether depressive symptoms and changes in depressive symptoms over time were associated with early retirement intentions.
\end{abstract}

Methods: We used a cross-sectional $(n=4041)$ and a prospective $(n=2444)$ population from a longitudinal study on employees of the Danish eldercare sector. Depressive symptoms were measured by the Major Depression Inventory and the impact of different levels of depressive symptoms (severe, moderately severe, moderate, mild and none) and changes in depressive symptoms (worsened, improved, unaffected) on early retirement intentions were analysed with multinomial logistic regression.

Results: In the cross-sectional analysis all levels of depressive symptoms were significantly associated with retirement intentions before the age of 62 years. Similar associations were found prospectively. Depressive symptoms and worsened depressive symptoms in the two year period from baseline to follow-up were also significantly associated with early retirement intentions before age 62 . The prospective associations lost statistical significance when controlling for early retirement intentions at baseline.

Conclusions: The whole spectrum of depressive symptoms represents a health related strain that can incur intentions to retire early by early voluntary retirement. In order to change the intentions to retire early, the work related consequences of depressive symptoms should be addressed as early in the treatment process as possible.

\section{Background}

The ageing work force challenges the economy of most Western countries and calls for new strategies to maintain people in the work force. Depression is a common mental disorder $[1,2]$ and is one of the leading causes of early retirement by disability pension in many Western Countries [2-12]. Although it is more common to retire early by other forms of retirement schemes than disability pension, it is poorly understood how depressive symptoms affect early voluntary retirement (EVR) plans.

\footnotetext{
* Correspondence: man@nrcwe.dk

${ }^{1}$ The National Research Centre for the Working Environment, Lersoe Parkallé 105, DK-2100 Copenhagen, Denmark

Full list of author information is available at the end of the article
}

EVR can be defined as early retirement by either selffinanced or publicly financed non-illness based pensions. Publicly financed EVR is available in a number of Western countries and is generally available at the age of 60 years or earlier [13]. Publicly financed EVR makes it economically viable for people to retire early. In 2001 in Denmark, approximately $40 \%$ of all citizens aged 60-64 years retired early by EVR [14]. Recently, most Western countries have gradually raised the official retirement age and the age at which publicly financed EVR is available [15]. Despite such restrictions, EVR remains the most common way of retiring early in Denmark [16-18].

Both 'pull' and 'push' factors can help explain people's incentives to retire early [19]. Factors that 'pull' people out of the labour market are mostly related to the 
prospect of a pleasurable retirement, such as a wish for self-actualization later in life or more time for leisure activities [20] e.g., being female and having a spouse that is retired have been associated with EVR [21]. Factors that 'push' people out of the labour market are often driven by a need to retire to relieve strain from, e.g., experienced health and medical problems [22, 23], increasing age, a poor work environment [24] or unemployment [17, 20]. In this regard, depression can be considered a push factor.

Depression is mostly characterised by an episodic course, but there is a high risk of relapse [25]. The core symptoms of depression are persistent low mood and marked loss of pleasure in usual activities [26, 27]. The symptoms affect most aspects of functioning including the ability to perform at work $[7,28,29]$ and often incur absence from work [30, 31]. Some symptoms and work disability can persist after a clinical depression has been treated [7, 28]. Two recent prospective studies found that having a depression increased the risk of EVR years later [32, 33] while one of the studies [32] found the same, but a less strong effect for sub-threshold depression, i.e., people experiencing symptoms not severe enough to reach the threshold of a clinical depression.

These prospective studies were based on betweengroup differences, i.e., people with depression were more likely to retire early than people without depression. By contrast, a study of within-person changes would measure whether changes in depression in the same person from one point in time to another affected early retirement [34]. Within-person measurements are needed in order to clarify whether improvements in depressive symptoms can change the intention to retire early.

Early retirement plans are likely to change over the course of one's life and can be viewed as a transitional process. A process which often begins with considerations and early retirement intentions then proceeds to a decision to retire early and eventually ends with actual retirement [35, 36]. Most of the longitudinal studies have examined the association between mental health and actual EVR [22, 23, 37, 38]. In order to prevent EVR due to mental health problems, it is important to identify factors that influence early retirement as early in the decision making process as possible. Two recent cross-sectional studies showed that poor mental health was strongly associated with early retirement intentions $[37,38]$. However, in order to clarify whether the retirement intentions were maintained over time, this association should be examined prospectively.

This study examined the association between depressive symptoms and early retirement intentions in four research questions:

1) Is the severity of depressive symptoms associated with immediate early retirement intentions?
2) Is the severity of depressive symptoms associated with early retirement intentions over a two-year period?

3) Are changes in depressive symptoms associated with early retirement intentions over a two-year period?

4) Do depressive symptoms affect changes in retirement intentions over time?

\section{Methods}

\section{Population}

This study used data from a prospective study of eldercare workers health and work characteristics [39]. Questionnaires were sent to all employees in the eldercare sector of 36 municipalities in Denmark over three waves: 2004/05 (Baseline), 2006/07 (Time 1: T1), and 2008/09 (Time 2: T2). Response rate at baseline was $78 \%$ accounting for 9949 of 12746 possible employees that answered the questionnaire. At T1, 10029 out of the 15697 possible employees responded (response rate $=64 \%$ ) and at T2, 8431 of 13945 possible employees responded (response rate $=61 \%$ ). Further details of this study can be found elsewhere $[39,40]$. In this study, we only used data from the 2006/07 and 2008/09 waves. The mean follow-up time was 24 months ranging between 22-26 months. We selected two study populations for the present study: A cross-sectional and a longitudinal population.

In the cross-sectional study population, we included participants who responded at T2 $(\mathrm{n}=8431)$. We excluded those participants who were below 45 or above 59 years at T2 $(\mathrm{n}=3490)$ and those who had missing values $(n=145)$, or who answered "I don't know" to the question about early retirement intentions $(n=755)$. The final cross-sectional population amounted to 4041. We did not have information on actual retirement, but in order to account for the possible bias of people who left the population because of EVR the participants were excluded at age 60 at T2. In Denmark, most employees can receive publicly financed EVR at the age of 60 (Danish: Efterløn) and the publicly financed old age pension at age 65 (Danish: Folkepension). Due to high Danish taxes on income self-financed retirement before the age of 60 is rare.

In the prospective study population, we included those participants who responded at both T1 and T2 $(\mathrm{n}=5206)$. We excluded participants who were below 45 or above 57 years old at $\mathrm{T} 1$ (i.e., above 59 years at $\mathrm{T} 2, \mathrm{n}=2336$ ) and who had turned 60 years at T2 $(\mathrm{n}=11)$. We also excluded participants, who had missing values $(n=25)$, or answered "I don't know" $(\mathrm{n}=390)$ to the question about early retirement intentions. The final prospective population consisted of 2444 employees.

This study was approved by the Danish Data Protection Agency. In Denmark, questionnaire studies require approval by the Danish Data Protection Agency, but not by 
an ethical committee. International ethical guidelines were nevertheless followed. Participants were informed about the study prior to participation and they were informed that participation was voluntary and that they could withdraw from the study at any time. They were also assured confidentiality.

\section{Depressive symptoms}

We measured depressive symptoms by the Major Depression Inventory (MDI). The MDI is a widely used self-rating scale to asses depression [41] according to both the DSM-IV [26] and ICD-10 [27] diagnostic classifications. The MDI has been validated in a Danish clinical setting and in the general population in Denmark [42, 43]. The MDI consists of 10 items that assess if depressive symptoms are present, for instance: "Have you felt low in spirits or sad"? or "Have you lost interest in your daily activities?". Using a six-point Likert scale, the items measure how frequent the symptoms have been present during the past two weeks $(0=$ The symptom is not present at all; $5=$ The symptom is present all the time). The individual responses to the items are summed up to a severity scale that ranges from 0 to 50 - the higher the score the more severe the depressive symptoms. A cut-off score of $\geq 20$ indicate a probable major depression. We categorised the MDI scores at T1 into five different categories indicating the severity of depressive symptoms:

1. 'Severe depressive symptoms' (scores $\geq 20$ );

2. 'Moderately severe depressive symptoms' (scores between 15 and 19);

3. 'Moderate depressive symptoms' (scores between 10 and 14);

4. 'Mild depressive symptoms' (scores between 5 and 9);

5. 'No depressive symptoms' (scores between 0 and 4).

Although a self-report questionnaire is able to indicate the presence of a clinical depression, a valid diagnosis can only be made by clinical assessment performed by a health care professional [26]. We therefore chose to describe the categories with a terminology referring to severity of depressive symptoms as opposed to categories such as 'major depression' or 'sub-threshold'depression. Severity of depressive symptoms at T2 was used as a predictor variable in the cross-sectional analyses.

Severity of depressive symptoms at $\mathrm{T} 1$ and changes in depressive symptoms from $\mathrm{T} 1$ to $\mathrm{T} 2$ were used as predictor variables in the longitudinal analyses. Changes in depressive symptoms had three categories: "Worsened", "improved" or "unaffected" symptoms. Participants were classified with "worsened symptoms" if their MDI score had increased five points or more and with "improved symptoms" if their MDI-score had decreased by five points or more. All other participants were classified with "unaffected symptoms".

\section{Outcome}

The intention to retire early was measured with a single item: "When would you like to retire from the labour market? Five response categories indicated age of intended retirement: "I would like to work until I turn 65 years old", "I would like to receive early retirement pension, when I am between 62 and 65 years old", "I would like to receive early retirement pension, when I am between 60 and 62 years old", "I would like to retire, before I turn 60 years old" or, "I don't know" These were recoded into three categories:

1 . Very early retirement intentions, which included the responses: 'I would like to retire before the age of 60' and 'when I am between 60 and 62 years old';

2 . Early retirement intentions, which included the response: 'I would like to retire when I am between 62 and 64 years old';

3. Normal retirement intentions, which included the response: 'I would like to work until I turn 65 years old';

Participants who answered "I don't know" were excluded from the study populations, as described previously.

\section{Statistical analyses}

Statistical analysis was conducted in PASW 18 (formally SPSS). Using multinomial logistic regression for the cross-sectional and prospective analyses, we examined the association of depressive symptoms with the probability of very early and early retirement intentions. A pvalue of $<0.05$ was regarded as statistically significant in these analyses. The cross-sectional analysis was adjusted for gender, age, marital status, working hours, seniority and type of occupation. We tested two models in the prospective analyses. Model 1 was adjusted for the same variables as the cross-sectional analysis. Model 2 was further adjusted for early retirement intentions at T1. The drop-out analyses were conducted using Pearson chi-square $\left(\chi^{2}\right)$.

\section{Results}

\section{Characteristics of study populations}

Table 1 shows the characteristics of the study population from the cross-sectional and longitudinal analyses.

\section{Cross-sectional analysis}

All levels of the elevated depressive symptoms were significantly associated with very early retirement intentions before age 62 (Table 2). Only mild and moderate levels of depressive symptoms, but not moderately severe or severe depressive symptoms, were significantly associated with early retirement intentions between ages 62 to 64 . 
Table 1 Characteristics of study populations ( $\%=$ percentage)

\begin{tabular}{|c|c|c|c|c|c|c|}
\hline \multicolumn{7}{|l|}{ Populations } \\
\hline & \multicolumn{4}{|c|}{ Longitudinal } & \multicolumn{2}{|c|}{ Cross-sectional } \\
\hline & $n=2444$ & & & & $n=4041$ & \\
\hline & $\mathrm{n}$ at $\mathrm{T1}$ & $\%$ & $\mathrm{n}$ at $\mathrm{T} 2$ & $\%$ & $\mathrm{n}$ at $\mathrm{T} 2$ & $\%$ \\
\hline Depressive symptoms & $\mathrm{MD}=153$ & $\mathrm{MD}=6$ & $\mathrm{MD}=171$ & $\mathrm{MD}=7$ & $M D=305$ & $M D=8$ \\
\hline Severe (MDI > =20) & 123 & 5 & 128 & 5 & 220 & 5 \\
\hline Moderately severe (MDI 15-19) & 139 & 6 & 139 & 6 & 234 & 6 \\
\hline Moderate (MDI 10-14) & 323 & 13 & 350 & 14 & 564 & 14 \\
\hline Mild (MDI 5-9) & 841 & 34 & 794 & 33 & 1293 & 32 \\
\hline None (MDI 0-4) & 865 & 35 & 862 & 35 & 1425 & 35 \\
\hline Change in depressive symptoms & & & $M D=296$ & $\mathrm{MD}=12$ & & \\
\hline Worsened & & & 360 & 15 & & \\
\hline Improved & & & 331 & 13 & & \\
\hline Unaffected & & & 1457 & 60 & & \\
\hline Retirement intentions & $M D=21$ & $\mathrm{MD}=8$ & & & & \\
\hline Very early (before 62) & 1357 & 56 & 1370 & 56 & 2136 & 53 \\
\hline Early (62 and 64 years) & 580 & 24 & 726 & 30 & 1216 & 30 \\
\hline Normal retirement (65 years) & 286 & 12 & 348 & 14 & 689 & 17 \\
\hline \multicolumn{7}{|l|}{ Age } \\
\hline $45-49$ years & 845 & 35 & & & 1116 & 28 \\
\hline $50-54$ years & 1024 & 42 & & & 1413 & 35 \\
\hline $55-60$ year & 575 & 24 & & & 1512 & 37 \\
\hline \multicolumn{7}{|l|}{ Gender } \\
\hline Male & 97 & 4 & & & 220 & 5 \\
\hline Female & 2347 & 96 & & & 3821 & 95 \\
\hline Marital status & $\mathrm{MD}=81$ & $\mathrm{MD}=3$ & & & $M D=61$ & $M D=1$ \\
\hline Cohabitant & 1966 & 81 & & & 3219 & 80 \\
\hline No cohabitant & 397 & 16 & & & 761 & 19 \\
\hline Shift work & $\mathrm{MD}=30$ & $\mathrm{MD}=1$ & & & $\mathrm{MD}=28$ & $\mathrm{MD}=1$ \\
\hline Day shift & 1595 & 65 & & & 2620 & 65 \\
\hline Night shift & 819 & 34 & & & 1393 & 34 \\
\hline Work experience & $\mathrm{MD}=39$ & $\mathrm{MD}=2$ & & & $M D=407$ & $M D=10$ \\
\hline $0-5$ years & 865 & 35 & & & 1549 & 38 \\
\hline $6-15$ years & 874 & 36 & & & 1069 & 27 \\
\hline$>=16$ years & 666 & 27 & & & 1016 & 25 \\
\hline Type of occupation & $\mathrm{MD}=15$ & $\mathrm{MD}=1$ & & & $\mathrm{MD}=25$ & $M D=1$ \\
\hline Supervisor & 241 & 10 & & & 405 & 10 \\
\hline Nurse or therapist & 258 & 10 & & & 457 & 11 \\
\hline Care helpers and assistants & 1702 & 70 & & & 2745 & 68 \\
\hline Other & 225 & 9 & & & 409 & 10 \\
\hline
\end{tabular}

$\mathrm{MD}=$ Missing data

\section{Prospective analysis}

'Moderately severe', 'moderate', and 'mild'- but not a 'severe' level of depressive symptoms at $\mathrm{T} 1$ were significantly associated with very early retirement intentions a T2 (Table 3). Only a 'mild' level of depressive symptoms was significantly associated with early retirement intentions between age 62 and 64 .

Worsened depressive symptoms from T1 to T2 significantly increased the risk of very early retirement intentions at T2, but not early retirement intentions 
Table 2 Cross-sectional analysis. Adjusted odds ratios (OR) for depressive symptoms at $\mathrm{T} 2$ and early retirement intentions at $\mathrm{T} 2$ $(n=4041)$

\begin{tabular}{|c|c|c|c|c|}
\hline \multirow[b]{4}{*}{ Depressive symptom at time 2} & \multicolumn{4}{|c|}{ Early retirement intentions } \\
\hline & \multicolumn{2}{|c|}{ Very early } & \multicolumn{2}{|l|}{ Early } \\
\hline & \multicolumn{2}{|c|}{ (before age 62) } & \multicolumn{2}{|c|}{ (age 62 to 64 ) } \\
\hline & OR & $(95 \% \mathrm{Cl})$ & OR & $(95 \% \mathrm{Cl})$ \\
\hline Severe $(\mathrm{MDI}>=20)$ & 2.11 & $(1.36-3.26)$ & 0.90 & $(0.54-1.50)$ \\
\hline Moderate severe (MDI 15-19) & 2.07 & $(1.34-3.19)$ & 1.16 & $(0.72-1.88)$ \\
\hline Moderate (MDI 10-14) & 2.03 & $(1.48-2.80)$ & 1.58 & $(1.13-2.21)$ \\
\hline Mild (MDI 5-9) & 1.59 & $(1.26-2.01)$ & 1.44 & $(1.13-1.84)$ \\
\hline None (MDI 0-4) & 1 & & 1 & \\
\hline
\end{tabular}

\section{Significant in bold}

MDI: Major Depression Index

* Reference group: Retirement at 65 years or above

OR adjusted for: Gender, age, marital status, shift work, work experience, type of occupation

(Table 3). Although not significant, there was a tendency that participants, who had improved their depressive symptoms, also had increased risk of early retirement intentions, compared to those who had unaffected symptoms.

After adjusting for retirement intentions at T1 (model 2 , Table 3) all of the prospective associations found in model 1 were no longer statistically significant.

\section{Attrition analyses}

The distribution of depressive symptoms in the selected cross-sectional and longitudinal study populations
(Table 1) was similar to the entire population of responders at T1 and T2. The percentage (\%) of all responders who had "severe" depressive symptoms at T1 ( $n=10029)$ was $6 \%$ and the percentage of all responders at T2 $(n=8431)$ was also $6 \%$. The percentage of all the responders represented in the other categories of depressive symptoms: "Moderately severe" T1 $=6 \%$ and T2 =6\%; "moderate" T1 = $13 \%$ and T2 = 14 \%; "mild" at T1 = $32 \%$ and $\mathrm{T} 2=31 \%$; "none" at $\mathrm{T} 1=36 \%$ and at $\mathrm{T} 2=34 \%$; and missing data of all responders at $\mathrm{T} 1=7 \%$ and at $\mathrm{T} 2=9 \%$.

The sample of dropouts consisted of those participants between 45-57 years at T1, who had not turned 60 at $\mathrm{T} 2$ and who had returned the questionnaire at $\mathrm{T} 1$ but not at T2 $(n=1467)$. Of this sample, $37 \%(n=541)$ did not return the questionnaire because they no longer worked at the particular workplace. Chi-square tests revealed that these non-responders were more likely to be married $(\mathrm{p}<0.05)$, be male $(\mathrm{p}<0.001)$, and have less years of work experience $(\mathrm{p}<0.001)$ compared to the responders from the prospective study population. No differences between depressive symptoms, age, shift work, or type of occupation were found.

Chi-square tests revealed that the non-responders who remained at the same work place $(n=926)$ were more likely to be male $(\mathrm{p}<0.001)$, to be younger $(\mathrm{p}<0.05)$, have less years of work experience $(\mathrm{p}<0.05)$, and to have more severe depressive symptoms $(\mathrm{p}<0.001)$ compared to the responders from the selected prospective study population. No differences between marital status, shift work, or type of occupation were found.

Table 3 Prospective analyses. Adjusted odds ratios (OR) for depressive symptoms at T1, changes in depressive symptoms from $\mathrm{T} 1$ to $\mathrm{T} 2$, and early retirement intentions at T2 $(n=2444)$

\begin{tabular}{|c|c|c|c|c|c|c|c|c|}
\hline & \multicolumn{8}{|c|}{ Early retirement intentions (T2) } \\
\hline & \multicolumn{4}{|c|}{ Model 1\# } & \multicolumn{4}{|c|}{ Model 2\#\# } \\
\hline & \multicolumn{2}{|c|}{ Very early } & \multirow{2}{*}{\multicolumn{2}{|c|}{$\begin{array}{l}\text { Early } \\
\text { (age } 62 \text { to } 64 \text { )* }\end{array}$}} & \multirow{2}{*}{\multicolumn{2}{|c|}{$\begin{array}{l}\text { Very early } \\
\text { (before age 62)* }\end{array}$}} & \multirow{2}{*}{\multicolumn{2}{|c|}{$\begin{array}{l}\text { Early } \\
\text { age } 62 \text { to } 64)^{*}\end{array}$}} \\
\hline & \multicolumn{2}{|c|}{$($ before age 62)* } & & & & & & \\
\hline & $\mathrm{OR}$ & $(95 \% \mathrm{Cl})$ & \multirow[t]{2}{*}{$\mathrm{OR}$} & \multirow[t]{2}{*}{$(95 \% \mathrm{Cl})$} & \multirow[t]{2}{*}{$\mathrm{OR}$} & \multirow[t]{2}{*}{$(95 \% \mathrm{Cl})$} & \multirow[t]{2}{*}{$\mathrm{OR}$} & \multirow[t]{2}{*}{$(95 \% \mathrm{Cl})$} \\
\hline Depressive symptoms at T & & & & & & & & \\
\hline Severe (MDI > =20) & 1.87 & $(0.87-4.03)$ & 1.31 & $(0.57-2.97)$ & 1.99 & $(0.57-7.00)$ & 1.64 & $(0.52-5.21)$ \\
\hline Moderate severe (15-19) & 2.05 & $(1.02-4.09)$ & 0.93 & $(0.42-2.05)$ & 1.76 & $(0.59-5.28)$ & 0.84 & $(0.29-2.39)$ \\
\hline (MDI 10-14) & 1.65 & $(1.02-2.66)$ & 1.46 & $(0.87-2.44)$ & 0.77 & $(0.38-1.56)$ & 0.89 & $(0.46-1.72)$ \\
\hline Mild (MDI 5-9) & 1.51 & $(1.08-2.07)$ & 1.72 & $(1.22-2.41)$ & 0.98 & $(0.60-1.59)$ & 1.21 & $(0.78-1.88)$ \\
\hline None (MDI 0-4) & \multicolumn{2}{|l|}{1} & \multicolumn{2}{|l|}{1} & \multicolumn{2}{|l|}{1} & \multicolumn{2}{|l|}{1} \\
\hline \multicolumn{9}{|c|}{ Change in depressive symptoms (from $\mathrm{T} 1$ to $\mathrm{T} 2$ ) } \\
\hline Worsened & 1.93 & $(1.27-2.94)$ & 1.49 & $(0.96-2.33)$ & 1.32 & $(0.72-2.43)$ & 1.18 & $(0.67-2.09)$ \\
\hline Improved & 1.34 & $(0.82-2.22)$ & 1.33 & $(0.78-2.25)$ & 1.31 & $(0.63-2.70)$ & 1.31 & $(0.66-2.55)$ \\
\hline Unchanged & \multicolumn{2}{|l|}{1} & \multicolumn{2}{|l|}{1} & \multicolumn{2}{|l|}{1} & \multicolumn{2}{|l|}{1} \\
\hline
\end{tabular}

\section{Significant in bold}

MDI: Major Depression Index

*Reference group: Retirement at 65 years or above

\# OR adjusted for: Gender, age, marital status, shift work, work experience, type of occupation

\#\# OR adjusted fro: Gender, age, marital status, shift work, work experience, type of occupation and early retirement intentions at T1 
Chi-square tests revealed that the participants who were excluded because they had answered "I don't know" to the question about early retirement intentions from both the cross-sectional and longitudinal study populations were significantly younger $(\mathrm{p}<0.05)$ than the study participants, but did not significantly differ with regards to depressive symptoms, gender, marital status, shift work, or work experience.

\section{Discussion}

The results from the cross-sectional analysis showed that all levels of elevated depressive symptoms doubled the chance of very early retirement intentions (before age 62), but not early retirement intentions (between ages 62 and 64). The same association was also found when examined over time, except that 'severe depressive symptoms' did not significantly affect intentions to retire before age 62. In addition, those who experienced worsened depressive symptoms over time were also more likely to have very early retirement intentions compared to those with no change in depressive symptoms. However, when adjusting for early retirement intentions at T1 in the longitudinal analyses, the results were no longer significant.

Our findings are in line with previous studies showing that depressive symptoms increase the risk of early retirement by either EVR [32, 33, 37, 38] or disability pension [8-11]. Whereas previous studies examined this association between groups only, we were also able to examine whether changes in depressive symptoms in the same person from one point in time to another influenced early retirement intentions. Worsened depressive symptoms were prospectively associated with very early retirement intentions [Odds Ratio: 1.93, 95 \% CI 1.27$2.94]$. We also found some indication that the early retirement intentions remained even after the depressive symptoms were relieved [Odds Ratio: 1.34, 95 \% CI $0.82-2.22]$, but these findings were not significant and therefore remains speculative.

We were also able to examine the association between depressive symptoms and changes in retirement intentions from $\mathrm{T} 1$ to $\mathrm{T} 2$. The prospective associations were no longer statistically significant when adjusting for retirement intentions at T1, regardless of the severity of depressive symptoms at $\mathrm{T} 1$ or whether the depressive symptoms had worsened or improved. A significant result after adjusting for retirement intentions at $\mathrm{T} 1$ would require that the retirement intentions increased from $\mathrm{T} 1$ to T2 among those participants who already had depressive symptoms and early retirement intentions at $\mathrm{T} 1$. Our finding indicated that the association between depressive symptoms and retirement intentions remained the same or was weakened in the two-year period.
In accordance with other recent studies, our study indicated that the presence of even mild depressive symptoms had significant work related consequences [30, 32, 44], including decisions to retire early by EVR [32]. The prospective, but not the cross-sectional, analyses failed to show that a severe level of depressive symptoms (indicating probable major depression) predicted early retirement, which contradicted the results of two previous studies [32, 33]. In our study, more non-responders were represented in the severe depressive symptoms category, which might have weakened the associations and might explain the non-significant findings.

It remains unknown whether the impact of depressive symptoms that are below the threshold of a clinical depression on early retirement should be understood as the effect of residual symptoms from a previous depression or as symptoms that reoccur independently. Our results in either case show that it is important to consider the whole spectrum of depression when analysing the impact of depression on EVR over time.

Our results may have been confounded by 'push' and 'pull' factors at T1. Studies have identified several factors that play an important role in both early retirement intentions and actual early retirement, such as an adverse working environment [24, 37, 38], spouses retirement status [45], being female [21], older age [46], and poor self-rated health and medical problems [22, 23]. We adjusted the results for most of these factors, but lack of control for comorbidity was an important limitation in our study. Two recent studies showed that the association of mental health and early retirement intentions remained even after adjusting for physical health, socioeconomic status, and spouses employment status [37, 38]. Comorbidity is, nevertheless, an important confounder that, had we controlled for it, could have weakened the associations.

Another important limitation of this study was the selective attrition. The response rate from the original study was fairly high [47], but we had to further restrict the study sample to only include participants between ages 45 and 59. Although selection bias was not introduced by excluding people from the study sample because of age, we also excluded a large proportion of the participants from the longitudinal sample because they had responded at $\mathrm{T} 1$, but not at $\mathrm{T} 2$.

Our attrition analyses showed that $37 \%$ of nonresponders no longer worked at the particular work place. Early retirement before the age of 60 is rare in Denmark [16, 48, 49] and since the eldercare sector in Denmark is characterised by a high degree of job change [50], it is likely that these non-responders dropped out of the study because they had changed jobs. However, our attrition analyses also showed that the nonresponders who remained at the same workplace were more likely to experience severe depressive symptoms 
than responders. This attrition can therefore have led to an underestimation of the findings.

The study population consisted of mainly female eldercare workers, an occupational group that is known for reporting a lower quality of the work environment compared to other sectors [39]. Thus, it is possible that our study population was more likely to have early retirement intentions than the general workforce. We attempted to account for this limitation by controlling for gender and work characteristics, but our results are primarily generalisable to older care workers in Western countries.

\section{Conclusions}

The whole spectrum of depressive symptoms represents a health related strain that can influence EVR. Our findings suggest that the severity of depressive symptoms can have an immediate impact on the intentions to retire early and that these intentions are maintained, but weakened over time. These findings also suggest that in order to change the intentions to retire early, the work related consequences of depressive symptoms should be addressed as early in the treatment process as possible.

\section{Competing interests}

The authors declare that they have no competing interest. None of the funding sources participated in any parts of the study.

\section{Authors' contributions}

MAN was responsible for design, data processing, statistical analyses, wrote the manuscript, and prepared it for publication. IGC supported the data-management process, analyses, and along with CSS and PUH contributed to the design, analysis, interpretations and discussion of the results. $R R$ contributed with suggestions that lead to changes in the design, analyses, and interpretations of the results. VB has supervised the entire process and contributed to the development of the idea and design of this study along with the analyses, and interpretations of the results. All authors have critically revised the initial draft of the manuscript and approved this final version of the manuscript.

\section{Acknowledgements}

This study was made possible by a grant from the Danish Working Environment Research Fund (ER 17-2009-03) and by a special grant from the Danish Parliament (satspulje 17-2009-03). We thank Kevin Lewis Hall, Insitderp Consulting, for improvement suggestions regarding English grammar and usage in this manuscript.

\section{Author details}

'The National Research Centre for the Working Environment, Lersoe Parkallé 105, DK-2100 Copenhagen, Denmark. '2Department of Public Health, University of Copenhagen, Oester Farimagsgade 5, Post box 2099, DK-1014 Copenhagen K, Denmark. ${ }^{3}$ Cancer Research UK partnership with the National Cancer Intelligence Network, Wellington House, 133-55 Waterloo Road, London SE1 8UG, U. K. Danish Institute for Local and Regional Government Research. Koebmagergade 22, DK-1150 Copenhagen K, Denmark. ${ }^{5}$ Department of Psychology, Copenhagen University, Oester Farigmagsgade 2A, DK-1353 Copenhagen, Denmark.

Received: 23 February 2015 Accepted: 25 June 2015

Published online: 17 July 2015

\section{References}

1. Murray JC. Quantifying the burden of disease: the technical basis for disability adjusted life years. Bull World Health Organ. 1994;72:429-45.
2. Murray JC, Lopez AD. The global burden of disease: a comprehensive assessment of mortality and disability from diseases, injuries, and risk factors in 1990 and projected on to 2020, vol. 1. Boston: Harvard University Press; 1996.

3. Mykletun A, Overland S, Dahl AA, Krokstad S, Bjerkeset O, Glozier N, et al. A population-based cohort study of the effect of common mental disorders on disability pension awards. Am J Psychiatry. 2006;163:1412-8.

4. OECD. Working paper awp 3.4. retirement income systems. Paris: The Reform Process Across OECD Countries; 1998.

5. OECD. Pensions at a glance 2009. Paris: Retirement income systems in OECD countries; 2006.

6. Kessler RC, Demler O, Frank RG, Olfson M, Pincus HA, Walters EE, et al. Prevalence and treatment of mental disorders, 1990 to 2003. New Engl J Med. 2005;352:2515-23.

7. Borg V, Nexo MA, Kolte IV, Andersen MA. White paper on mental health, sickness absence and return to work [translated from Danish: hvidbog om mentalt helbred, sygefravær og tilbagevenden til arbejde]. Copenhagen: The National Research Center for the Working Environment; 2010.

8. Gjesdal S, Ringdal PR, Haug K, Maeland JG. Long-term sickness absence and disability pension with psychiatric diagnoses: a population-based cohort study. Nord J Psychiatry. 2008;62:294-301.

9. Karlsson NE, Carstensen JM, Gjesdal S, Alexanderson KA. Risk factors for disability pension in a population-based cohort of men and women on long-term sick leave in Sweden. Eur J Public Health. 2008;18:224-31.

10. Kivimaki M, Ferrie JE, Hagberg J, Head J, Westerlund $H$, Vahtera J, et al. Diagnosis-specific sick leave as a risk marker for disability pension in a Swedish population. J Epidemiol Community Health. 2007;61:915-20.

11. Vaez M, Rylander G, Nygren A, Asberg M, Alexanderson K. Sickness absence and disability pension in a cohort of employees initially on long-term sick leave due to psychiatric disorders in Sweden. Soc Psychiatry Psychiatr Epidemiol. 2007:42:381-8.

12. Wallman $\mathrm{T}$, Wedel $\mathrm{H}$, Palmer E, Rosengren A, Johansson S, Eriksson $\mathrm{H}$, et al. Sick-leave track record and other potential predictors of a disability pension. a population based study of 8,218 men and women followed for 16 years. BMC Public Health. 2009;9:104.

13. Ippolito RA. Toward explaining earlier retirement after 1970. Indus Labor Rel Review. 1990;43:556-69.

14. Pedersen L, Tranæs T. The Danish labour market [translated from Danish: Det danske arbejdsmarked]. Copenhagen: The National Institute of Social Research; 2004.

15. OECD. Pensions at a glance: OECD and G20 indicators. Paris: OECD publishing; 2013.

16. Statistics Denmark. People on Public Benefits [Translated from Danish: Offentligt forsørgede]. http://www.dst.dk/da/Statistik/emner/offentligtforsoergede.aspx. (Accessed June 29, 2015)

17. Jensen LD, Ryom PK, Christensen MV, Andersen JH. Differences in risk factors for voluntary early retirement and disability pension: a 15-year follow-up in a cohort of nurses' aides. Bmj Open. 2012;2:6.

18. Nielsen TM. Transition into voluntary early retirement [Translated from Danish: Overgang til efterløn]. Copenhagen: Danmarks Statistik; 2005.

19. Shultz KS, Morton KR, Weckerle JR. The influence of push and pull factors on voluntary and involuntary early retirees' retirement decision and adjustment. J Vocat Behav. 1998:53:45-57.

20. Siegrist J, Wahrendorf $M$, von dem Knesebeck O, Juerges $H$, Borsch-Supan A Quality of work, well-being, and intended early retirement of older employees - baseline results from the SHARE Study. Eur J Public Health. 2007:17:62-8.

21. von Bonsdorff ME, Huuhtanen P, Tuomi K, Seitsamo J. Predictors of employees' early retirement intentions: an 11-year longitudinal study. Occup Med-Oxford. 2010;60:94-100

22. Olesen SC, Butterworth P, Rodgers B. Is poor mental health a risk factor for retirement? findings from a longitudinal population survey. Soc Psychiatry Psychiatr Epidemiol. 2012;47:735-44

23. Pit SW, Shrestha R, Schofield D, Passey M. Health problems and retirement due to ill-health among Australian retirees aged $45-64$ years. Health Policy. 2010:94:175-81.

24. Sejbaek CS, Nexo MA, Borg V. Work-related factors and early retirement intention: a study of the Danish eldercare sector. Eur J Public Health. 2013;23:611-6

25. Belsher G, Costello CG. Relapse after recovery from unipolar depression - a critical-review. Psychol Bull. 1988;104:84-96. 
26. American Psychiatric Association. Diagnostic and statistical manual of mental disorders. Washington DC: American Psychiatric Association; 2000.

27. World Health Organization. International classification of diseases. 10th revision. Geneva: WHO; 2010

28. Sanderson K, Tilse E, Nicholson J, Oldenburg B, Graves N. Which presenteeism measures are more sensitive to depression and anxiety? J Affect Disord. 2007;101:65-74.

29. Schultz $A B$, Edington DW. Employee health and presenteeism: a systematic review. J Occup Rehabil. 2007;17:547-79.

30. Hjarsbech PU, Andersen RV, Christensen KB, Aust B, Borg V, Rugulies R. Clinical and non-clinical depressive symptoms and risk of long-term sickness absence among female employees in the Danish eldercare sector. J Affect Disord. 2011;129:87-93.

31. Thorsen SV, Rugulies R, Hjarsbech PU, Bjorner JB. The predictive value of mental health for long-term sickness absence: the Major Depression Inventory (MDI) and the Mental Health Inventory (MHI-5) compared. BMC Med Res Methodol. 2013;13:115.

32. Doshi JA, Cen L, Polsky D. Depression and retirement in late middle-aged U.S. workers. Health Serv Res. 2008;43:693-713.

33. Karpansalo M, Kauhanen J, Lakka TA, Manninen P, Kaplan GA, Salonen JT. Depression and early retirement: prospective population based study in middle aged men. J Epidemiol Community Health. 2005;59:70-4.

34. Ng TWH, Feldman DC. How do within-person changes due to aging affect job performance? J Vocat Behav. 2013;83:500-13.

35. Beehr TA. The process of retirement - a review and recommendations for future investigation. Pers Psychol. 1986;39:31-55.

36. Topa G, Moriano JA, Depolo M, Alcover CM, Morales JF. Antecedents and consequences of retirement planning and decision-making: a meta-analysis and model. J Vocat Behav. 2009;75:38-55.

37. Harkonmaki K, Rahkonen O, Martikainen P, Silventoinen K, Lahelma E. Associations of SF-36 mental health functioning and work and family related factors with intentions to retire early among employees. Occup Environ Med. 2006;63:558-63.

38. Harkonmaki K, Lahelma E, Martikainen P, Rahkonen O, Silventoinen K. Mental health functioning (SF-36) and intentions to retire early among ageing municipal employees: the Helsinki health study. Scand J Public Health. 2006;34:190-8.

39. Borg V, Carneiro IG, Clausen T, Faber A. The working environment in the eldercare sector in Denmark. Results and conclusions [Translated from Danish: Arbejdsmiljø i ældreplejen i Danmark. Resultater og konklusioner]. Copenhagen: The National Research Center for the Working Environment; 2007.

40. Rugulies R, Madsen IEH, Hjarsbech PU, Hogh A, Borg V, Carneiro IG, et al. Bullying at work and onset of a major depressive episode among Danish female eldercare workers. Scand J Work Env Hea. 2012;38:218-27.

41. Cuijpers P, Dekker J, Noteboom A, Smits N, Peen J. Sensitivity and specificity of the major depression inventory in outpatients. Bmc Psychiatry. 2007;7.

42. Bech P, Rasmussen NA, Olsen LR, Noerholm V, Abildgaard W. The sensitivity and specificity of the Major Depression Inventory, using the Present State Examination as the index of diagnostic validity. J Affect Disord. 2001;66:159-64.

43. Olsen LR, Jensen DV, Noerholm V, Martiny K, Bech P. The internal and external validity of the Major Depression Inventory in measuring severity of depressive states. Psychol Med. 2003;33:351-6.

44. Cuijpers P, Smit F. Subthreshold depression as a risk indicator for major depressive disorder: a systematic review of prospective studies. Acta Psychiatr Scand. 2004;109:325-31.

45. Van Dam K, van der Vorst JDM, van der Heijden BIJM. Employees' intentions to retire early a case of planned behavior and anticipated work conditions. J Career Dev. 2009;35:265-89.

46. Taylor MA, Shore LM. Predictors of planned retirement age - an application of beehrs model. Psychol Aging. 1995;10:76-83.

47. Galea S, Tracy M. Participation rates in epidemiologic studies, Ann Epidemiol. 2007;17:643-53.

48. Friis K, Ekholm O, Hundrup YA, Obel EB, Gronbiek M. Influence of health, lifestyle, working conditions, and sociodemography on early retirement among nurses: the Danish nurse cohort study. Scand J Public Health. 2007:35:23-30.

49. Schaarup J. The Age at Retirement 1992-2008 [Tilbagetrækningsalderen 1992-2008]. The Danish Insurance Association: Copenhagen; 2009.

50. Tufte $P$, Borg V. Retaining employees in the eldercare sector [Translated from Danish: fastholdelse af medarbejdere i ældreplejen]. Copenhagen: The National Research Center for the Working Environment; 2007.

\section{Submit your next manuscript to BioMed Central and take full advantage of:}

- Convenient online submission

- Thorough peer review

- No space constraints or color figure charges

- Immediate publication on acceptance

- Inclusion in PubMed, CAS, Scopus and Google Scholar

- Research which is freely available for redistribution

Submit your manuscript at www.biomedcentral.com/submit 